\title{
Comparisons of heart-type fatty acid-binding protein (H-FABP) levels in off-pump versus on-pump coronary artery bypass grafting
}

Mustafa Ozer Ulukan ${ }^{1}$, Murat Ugurlucan², Orcun Unal ${ }^{3}$, Muhammet Fatih Yılmaz ${ }^{1}$, Nilgun Kasifoglu ${ }^{4}, M$. Behcet Sevin ${ }^{1}$

\author{
${ }^{1}$ Department of Cardiovascular Surgery, Faculty of Medicine, Osmangazi University, \\ Eskisehir, Turkey \\ ${ }^{2}$ Department of Cardiovascular Surgery, Medical Faculty, Istanbul University, Istanbul, \\ Turkey \\ ${ }^{3}$ Department of Cardiovascular Surgery, Bakırkoy Dr.Sadi Konuk Teaching and \\ Research Hospital, Bakırkoy-Istanbul, Turkey \\ ${ }^{4}$ Department of Microbiology, Faculty of Medicine, Osmangazi University, Eskisehir, \\ Turkey
}

Submitted: 23 December 2018

Accepted: 23 April 2019

Arch Med Sci Atheroscler Dis 2019; 4: e119-e125

DOI: https://doi.org/10.5114/amsad.2019.85426

Copyright $\odot 2019$ Termedia \& Banach

\section{Abstract}

Introduction: Heart-type fatty acid-binding protein (H-FABP) is a novel indicator of myocardial damage. The aim of the study was to compare the levels of H-FABP in off-pump and on-pump coronary artery bypass grafting (CABG). Material and methods: Thirty non-randomised 30 patients who underwent CABG between January 2009 and January 2010 were enrolled in the study. Patients were divided into two equal size $(n=15)$ groups as group A (offpump CABG group) and group B (on-pump CABG group). Three arterial blood samples were obtained for H-FABP after sternotomy (H-FABP 1), after the last distal anastomosis in group $A$ and immediately after the cross clamp was removed from the aorta in group B (H-FABP 2) and $24 \mathrm{~h}$ after the operation (H-FABP 3). Renal and liver functions and circulating fatty acid binding protein (FABP) levels were also assessed in blood samples obtained $24 \mathrm{~h}$ before and $1 \mathrm{~h}$ after the operation.

Results: At all three assessment points patients in group B had significantly higher H-FABP values when compared with group A. Preoperative renal and liver functions were similar in both groups and they did not differ significantly in group A and group B when preoperative and postoperative values were compared. In both groups circulating FABP levels increased in the postoperative period, and the increase was more pronounced in the on-pump CABG group.

Conclusions: On-pump surgery resulted in higher levels of H-FABP as an ischaemic marker in patients receiving coronary artery bypass surgery.

Key words: coronary artery bypass grafting, off-pump, beating heart, metabolic process, fatty acid-binding globulin, myocardial-specific.

\section{Introduction}

Since the beginning of coronary artery bypass surgery, cardiopulmonary bypass (CPB) has been an inevitable component of the procedure. In elective conditions mortality rates are reported between $2 \%$ and $3 \%$

\author{
Corresponding author: \\ Mustafa Ozer Ulukan \\ Department of \\ Cardiovascular Surgery \\ Faculty of Medicine \\ Osmangazi University \\ Eskisehir, Turkey \\ E-mail: ozerulukan@hotmail. \\ com
}


[1]. On-pump coronary bypass grafting provides a bloodless and stable surgical field, which is an optimum condition for coronary artery bypass grafting (CABG) [2]. However, it leads to systemic inflammatory response, which may affect lungs, heart, kidney, and brain [3]. Cardioplegic arrest and aortic cross clamping also add additional ischaemia, which may lead to additional injury to the heart and brain [4].

Off-pump CABG is a less invasive procedure when compared with on-pump surgery [1-4]. However, a less stable and less visible surgical field make surgery technically more demanding than on-pump surgery [4]. After the 1990s, development of cardiac stabilisers made off-pump surgery more feasible. In recent years, off-pump coronary artery bypass application has increased with an idea to minimise the insult of CPB to the body during surgical revascularisation [5]. Upon avoiding CPB, myocardial ischaemia-reperfusion damage decreases and postoperative systemic complications fall clearly [6]. Previous reports indicate shorter hospital stay, less need for transfusion, reduced atrial fibrillation frequency, and fewer myocardial infarctions $[2,4]$.

Our purpose in this study was to assess the changes of heart-type fatty acid-binding protein (H-FABP) as a marker of ischaemia in patients undergoing off-pump and on-pump CABG in a prospective controlled manner.

\section{Material and methods}

This study was performed at the O.U.M.F. The study protocol was approved by the institutional Ethics Committee. Written, informed consent was obtained from all subjects. The technique of operation was chosen regarding the patients' coronary lesions, and we tried to ensure full revascularisation in all cases.

This was a non-randomised study, and during the study period 15 subjects who had undergone off-pump CABG were enrolled to the off-pump group (group A), whereas 15 subjects who underwent on-pump CABG were enrolled to the onpump group (group B) during the same period. In both groups, subjects who were not willing to join the study, subjects who underwent re-do cardiac surgery, patients receiving additional valvular or aortic surgery, patients with a recent myocardial infarction, emergent operations, chronic renal or hepatic diseases, and patients with diabetes mellitus were excluded from the study.

Demographic parameters of the patients: body mass index (BMI), ejection fraction (EF), postoperative extubation time, and amount of postoperative drainage were noted. Intraoperative vein graft type and number of anastomoses were also recorded. Subjects were also evaluated for met- abolic parameters, namely alanine transaminase (ALT), aspartate transaminase (AST), blood urea nitrogen (BUN), creatinine, BUN/creatinine ratio, and $\mathrm{H}-\mathrm{FABP}$.

\section{Measurement of metabolic parameters}

Arterial blood samples were obtained for $\mathrm{H}-\mathrm{FABG}$ three times. The first samples were obtained after sternotomy in both groups (H-FABP $1)$. The second samples were obtained after the last distal anastomosis in group A (H-FABP 2). In group $B$ the second blood samples were obtained immediately after the removal of the aortic cross clamp (H-FABP 2). The third samples were obtained at the $24^{\text {th }} \mathrm{h}$ after the operation (H-FABP 3 ).

Arterial blood samples were drawn into the plastic tubes containing $1 \mathrm{mg} / \mathrm{ml}$ ethylenediamine-tetra acetic acid (EDTA). The sera, which was provided from blood samples by centrifuging for $3500 \mathrm{rpm}$ for $5 \mathrm{~min}$, were stored at $-70^{\circ} \mathrm{C}$. H-FABP measurements were performed by the Department of Microbiology, ELISA Laboratory by using H-FABP ELISA Kit (Life Diagnostics Inc., West Chester, USA). Normal values were accepted as 1.6-19 $\mathrm{ng} / \mathrm{ml}$, and $>19$ was accepted as a marker of myocardial infarction. The measurements of ALT, AST, BUN, and creatinine values were performed twice. Venous blood samples were obtained $24 \mathrm{~h}$ before the operation and $1 \mathrm{~h}$ after the operation.

\section{Anaesthesia technique}

Premedication was provided with a $0.05 \mathrm{mg}$ / kg morphine intramuscular injection $30 \mathrm{~min}$ before the operation in both groups. The subjects were taken on the operation table and monitored. For induction, all subjects were administered $0.3 \mathrm{mg} / \mathrm{kg}$ etomidate intravenously. Respiration was taken under control with a mask following the loss of consciousness and lash. Neuromuscular blocker (0.9 $\mathrm{mg} / \mathrm{kg}$ rocuronium) was given. The subjects were introduced sevoflurane volatile anaesthesia with a value of 2-4 minimum alveolar concentration (MAC). After $3 \mathrm{~min}$, intubation was performed and the subjects were connected to a mechanical ventilator. For central venous pressure follow-up an $8 \mathrm{Fr}$ catheter was placed in the right internal jugular vein. An oesophageal heat probe was placed for heat tracking during the surgical operation, and a Foley urine catheter was placed for kidney functions. The subjects were started with a $0.1-0.4 \mu \mathrm{g} / \mathrm{kg} / \mathrm{min}$ remifentanil infusion. Mechanical ventilation was applied in controlled mechanical ventilation mode. When superficial anaesthesia symptoms were detected sevoflurane doses were increased. Upon ending of the surgery anaesthetic agents were stopped and the subject was transferred to an intensive care 
unit. After the anaesthesia blood pressures were monitored through a radial artery catheter, and central venous pressures were monitored through an internal jugular vein catheter.

\section{Surgical procedure}

In both groups the left internal mammary artery (LIMA) and saphenous vein grafts were prepared after median sternotomy. The pericardium was opened and traction sutures were placed. In group $A$ the patients were heparinised as the activated clotting time (ACT) level would be between 200 and 250 s. First, proximal anastomoses were done on side-clamped ascending aorta. The zone to which the anastomosis was applied was stabilised using Octopus ${ }^{\circledR}$ II (Medtronic Inc., Minneapolis, $M N$ ) equipment. Coronary arteriotomy was performed. An intracoronary shunt was not used for distal anastomosis. The coronary arteries were occluded from proximal and distal segments by bulldog vascular clamps. The distal anastomosis of saphenous vein grafts was performed in an end-to-side fashion with a 7/0 polyproline running suture. Finally, the LIMA-LAD (left anterior descending artery) anastomosis was performed in the same manner. Heparin was neutralised with protamine after the anastomoses.

In group $B$ ascending aortic and two-stage venous cannulations were performed. Extracorporeal circulation was started. The aorta was cross clamped. Antegrade blood cardioplegia was infused through the aortic root cannula. Cardiac arrest was provided. Moderate $\left(30-32^{\circ} \mathrm{C}\right)$ hypothermia was achieved by the pump. A Jostra ${ }^{\circledR}$-coated oxygenator (Jostra Medizintechnik AG, Hirrlingen, Germany) was utilised. While performing LIMA-LAD anastomosis, the subjects were heated gradually. The cross clamp was removed, and proximal anastomoses were on the side-clamped ascending aorta during CPB. After the proximal anastomoses, patients were gradually weaned off the cardiopulmonary bypass.

\section{Statistical analysis}

Static analysis of all variables was performed with SPSS (Statistical Analysis for Social Sciences) version 19 (IBM Corporation, USA). For normally distributed variables $t$-test, two-way variance analysis, and two-tailed exact sigma test were used. Indicating statistics were given as average \pm standard error (mean $\pm \mathrm{SE}$ ). For variables not normally distributed the Mann-Whitney $U$ and Wilcoxon signed-rank test were performed, and the results were given as its median, and $25^{\text {th }}$ and $75^{\text {th }}$ percentile values. Descriptive analyses were presented as percentages. A $p$-value less than 0.05 was accepted as statistically significant.

\section{Results}

\section{Comparison of demographic data}

The study included 30 subjects. Twelve out of the 30 subjects were female and the remaining 18 were male. Both groups consisted of 15 subjects. Group A consisted of eight males and seven females, whereas group B consisted of 9 males and 6 females. There were no significant differences for gender distribution, $\mathrm{BMI}, \mathrm{EF}$, and history of diabetes between groups $(p=0.080, p=0.087, p=0.130$, $p=0.060$, respectively). The age and $\mathrm{FEV}_{1}$ levels differed between patients in groups. Patients in group $B$ had significantly higher age and higher $\mathrm{FEV}_{1}$ levels when compared with the patients in group A (59.00 \pm 9.9 vs. $66.40 \pm 9.4$ years, $p=0.045$ for age and $76.20 \pm 9.1 \%$ vs. $84 \pm 10.3 \%, p=0.037$ for $\mathrm{FEV}_{1}$ ) (Table I).

\section{Intraoperative and postoperative parameters}

LIMA was used in 12 subjects in group $A$ and 13 subjects in group $B$. No significant difference existed for LIMA use between groups ( $p=1.000$ ). Saphenous vein graft use differed between groups. In group $B$, patients received significantly higher

Table I. Comparison of age, BMI, EF, $\mathrm{FEV}_{1}$, and amount of postoperative drainage between groups

\begin{tabular}{|c|c|c|c|c|c|}
\hline Parameter & Group & $N$ & Mean & Standard deviation & $P$-value \\
\hline \multirow[t]{2}{*}{ Age [year] } & $A$ & 15 & 59.00 & 9.907 & $<0.05$ \\
\hline & B & 15 & 66.40 & 9.402 & \\
\hline \multirow[t]{2}{*}{ BMI } & A & 15 & 28.18 & 2.614 & $>0.05$ \\
\hline & B & 15 & 30.51 & 4.319 & \\
\hline \multirow[t]{2}{*}{$\mathrm{FEV}_{1}(\%)$} & A & 15 & 76.20 & 9.127 & $<0.05$ \\
\hline & B & 15 & 84.00 & 10.323 & \\
\hline \multirow[t]{2}{*}{ EF (\%) } & A & 15 & 46 & 14.533 & $>0.05$ \\
\hline & B & 15 & 53 & 8.236 & \\
\hline \multirow[t]{2}{*}{ Drainage [ml] } & A & 15 & 714 & 283 & $>0.05$ \\
\hline & $\mathrm{B}$ & 15 & 779 & 278 & \\
\hline
\end{tabular}

$B M I-$ body mass index, $F E V_{1}$ - forced expiratory volume in $1 \mathrm{~s}$, EF-ejection fraction. 
numbers of saphenous vein graft conduits $(p<$ 0.001 , Table II). Radial artery graft was used only in one subject in group B. There was a significant difference between groups when the number of distal anastomosed vessels was compared. In group A, one and two vessels were anastomosed in six and nine subjects, and in group B two, three, and four vessels were anastomosed in two, 10, and three subjects, respectively ( $p<0.001$, Table III). Only two subjects needed intra-aortic balloon pump (IABP) support due to low EF and occurrence of hypotension at the time of distal anastomosis, and they were from group A. Although these patients were supported with high doses of inotropic drug infusion, their mean blood pressures were low, so they were supported with IABP counterpulsation, and after stable, reasonable target values of mean arterial pressure of $65 \mathrm{~mm} \mathrm{Hg}$ were reached, IABP counterpulsations were weaned and removed. There was no statistical difference between groups regarding postoperative drainage $(714 \pm 283 \mathrm{ml}$ for group $\mathrm{A}$ and $779 \pm 278 \mathrm{ml}$ for group $\mathrm{B}, p=0.529$ ).

Mean operation time was shorter in the off-pump group than in the on-pump group (165 vs. $215 \mathrm{~min}$, $p=0.02$ ). Median extubation time was $210 \mathrm{~min}$ in group $A$ and 360 min in group $B(p<0.001)$.

\section{Metabolic parameters}

The median values of the preoperative and postoperative ALT, AST, BUN, creatinine, and BUN/creatinine ratio are presented in Table IV. In group $A$, when preoperative and postoperative values were compared, no significant difference existed for ALT, creatinine levels, and BUN/creatinine ratio ( $p=0.254, p=0.471, p=0.245$, respectively); however, the AST and BUN levels were lower in the postoperative period ( $p=0.017$ and $p=0.020$, respectively).

In group B, ALT and BUN levels significantly increased in the postoperative samples (21 vs. 42

Table II. Comparison of saphenous vein use between groups

\begin{tabular}{|c|c|c|c|c|c|}
\hline \multirow[t]{2}{*}{ Group } & \multicolumn{4}{|c|}{ Number of saphenous vein grafts } & \multirow[t]{2}{*}{$P$-value } \\
\hline & 0 & 1 & 2 & 3 & \\
\hline$A^{b}$ & 3 & 12 & 0 & 0 & $<0.001^{* *}$ \\
\hline $\mathrm{B}^{\mathrm{b}}$ & 0 & 3 & 7 & 5 & \\
\hline
\end{tabular}

${ }^{b}$ Pearson $\chi^{2},{ }^{* *} p<0.001$

Table III. Number of anastomosed vessels in groups

\begin{tabular}{|lcccccccc|}
\hline Group & \multicolumn{4}{c}{ Number of anastomosed vessels } & \multicolumn{3}{c}{ Percentiles } & \multirow{2}{*}{-value } \\
\cline { 2 - 7 } & $\mathbf{1}$ & $\mathbf{2}$ & $\mathbf{3}$ & $\mathbf{4}$ & $\mathbf{2 5}$ & Median & $\mathbf{7 5}$ & \\
\hline $\mathrm{A}^{\mathrm{b}}$ & 6 & 9 & 0 & 0 & 1.0 & 2.0 & 2.0 & $<0.001^{\text {** }}$ \\
\hline $\mathrm{B}^{\mathrm{b}}$ & 0 & 2 & 10 & 3 & 3.0 & 3.0 & 3.0 & \\
\hline
\end{tabular}

Table IV. Comparison of preoperative and postoperative values of ALT, AST, BUN, creatinine and BUN/creatinine between groups

\begin{tabular}{|lccccccc|}
\hline Parameter & Group & \multicolumn{3}{c}{ Preop. percentiles } & \multicolumn{3}{c|}{ Postop. percentiles } \\
\cline { 2 - 8 } & & $\mathbf{2 5}$ & Median & $\mathbf{7 5}$ & $\mathbf{2 5}$ & Median & $\mathbf{7 5}$ \\
\hline ALT [U/l] & $\mathrm{A}$ & 22 & 27 & 49 & 18 & 26 & 30 \\
\cline { 2 - 8 } & $\mathrm{B}$ & 17 & 21 & 22 & 35 & 42 & 56 \\
\hline AST [U/l] & $\mathrm{A}$ & 19 & 30 & 37 & 14 & 18 & 32 \\
& $\mathrm{~B}$ & 14 & 18 & 23 & 14 & 23 & 37 \\
\hline BUN [mg/dl] & 1 & 14 & 17 & 24 & 14 & 17 & 18 \\
\hline & 2 & 18 & 21 & 25 & 24 & 27 & 32 \\
\hline Creatinine [mg/dl] & 1 & 0.8 & 1 & 1 & 0.8 & 0.8 & 1 \\
\cline { 2 - 8 } & 2 & 0.9 & 1 & 1.3 & 1 & 1.2 & 1.5 \\
\hline BUN/creatinine & 1 & 16 & 20 & 24 & 17 & 18 & 21 \\
& 2 & 17 & 21 & 24 & 21 & 23 & 26 \\
\hline
\end{tabular}


Table V. Levels of heart-type fatty acid-binding protein at assessment points

\begin{tabular}{|c|c|c|c|c|c|}
\hline \multirow[t]{2}{*}{ H-FABP } & \multirow[t]{2}{*}{ Group } & \multicolumn{3}{|c|}{ Percentiles } & \multirow[t]{2}{*}{$P$-value } \\
\hline & & 25 & Median & 75 & \\
\hline \multirow{2}{*}{$\begin{array}{l}\text { H-FABP } 1 \\
\text { (after sternotomy) }\end{array}$} & A & 0.80 & 1.40 & 2.90 & \multirow[t]{2}{*}{$<0.01$} \\
\hline & B & 2.60 & 3.10 & 4.50 & \\
\hline \multirow{2}{*}{$\begin{array}{l}\text { H-FABP } 2 \\
\text { (after the removal of aortic cross clamp/ } \\
\text { last distal anastomosis) }\end{array}$} & A & 1.90 & 2.75 & 4.00 & \multirow[t]{2}{*}{$<0.001$} \\
\hline & B & 4.70 & 10.10 & 15.00 & \\
\hline \multirow{2}{*}{$\begin{array}{l}\text { H-FABP } 3 \\
\text { ( } 24^{\text {th }} \text { postoperative hour) }\end{array}$} & A & 0.75 & 1.40 & 2.40 & \multirow[t]{2}{*}{$<0.01$} \\
\hline & B & 2.30 & 3.20 & 12.00 & \\
\hline
\end{tabular}

H-FABP - heart-type fatty acid-binding protein.

for ALT, $p<0.001$ and 21 vs. 27 for BUN $p=0.006$ ). When preoperative and postoperative values were compared, no significant difference existed for AST, creatinine levels, and BUN/creatinine ratio $(p=0.124, p=0.016, p=0.186$, respectively).

$\mathrm{H}$-FABP levels in all three assessment points indicated a statistically significant difference between groups. Group B had significantly higher $\mathrm{H}$-FABP values when compared with group $\mathrm{B}$ in all three assessment points (1.40 ng/dl vs. $3.10 \mathrm{ng} / \mathrm{dl}$ for H-FABP1, $p=0.004 ; 2.75 \mathrm{ng} / \mathrm{dl}$ vs. $10.10 \mathrm{ng} / \mathrm{dl}$ for H-FABP2, $p<0.001$, and $1.40 \mathrm{ng} / \mathrm{dl}$ vs. $3.20 \mathrm{ng} / \mathrm{dl}$ for H-FABP3, $p=0.006$, Table V). The H-FABP values were also compared in patients in group $A$ and $B$. The H-FABP values did not differ significantly at different time points in group A (H-FABP1: 1.40 ng/dl, H-FABP2: 2.75 ng/dl, H-FABP3: 1.40 ng/dl; $p=0.15)$. However, in group $B$, the H-FABP 2 levels $(10.10 \mathrm{ng} / \mathrm{dl})$ were found to be significantly increased when compared with H-FABP 1 (3.10 ng/dl) and H-FABP $3(3.20 \mathrm{ng} / \mathrm{dl})$. In the same group, H-FABP 1 (3.10 ng/dl) and H-FABP 3 (3.20 ng/dl) were measured and found to be similar (Figure 1).

\section{Discussion}

Off-pump CABG surgery may be preferable in certain cases because it results in lower surgical trauma when compared with on-pump surgery. In the literature various advantages of off-pump surgery have been reported previously [7]. Off-pump CABG provides protection against pump lung syndrome [8]. The lung damage caused by CPB ranges from microatelectasis to acute respiratory distress syndrome [9]. An increase in extubation time also increases the risks of atelectasis, aspiration pneumonia, and swallowing problems and is related with increased mortality and morbidity risk. The risk of lung damage significantly increases when the extubation time exceeds 150 min [10]. In our study, although respiratory function tests were better in the on-pump group, extubation times were shown to be longer than for off-pump. The extubation time was, on average, $210 \mathrm{~min}$ in group A and 360 min in group B $(p<0.001)$. Administration of lower doses of heparin, avoidance of CPB-related haemodilution, extracorporeal circulation, and hypothermia-related coagulopathy results in less perioperative bleeding and reduced need for heterologous transfusion [11].

In a prospective study Yamada et al. evaluated transient hepatocellular damage in 38 subjects (17 off-pump; 21 on-pump) by measuring alcohol dehydrogenase (AD) and $\alpha$-glutathione S-transferase $(\alpha-G S T)$. Both markers have been found to significantly rise in the on-pump group postoperatively [12]. In a recent study on 50 subjects (25 offpump; 25 on-pump) Möhnle et al. evaluated the effect of surgery type on hepatic function and perfusion in subjects without pre-existing liver function [13]. Plasma indocyanine green clearance as well as standard laboratory tests were similar in the groups. In our study, in group A no significant difference existed in preoperative and postoperative values in terms of ALT. AST levels decreased in the postoperative period. In group $B$, the preoperative and postoperative change of AST was not significant. ALT levels significantly increased in postoperative measurement.

Renal impairment and acute renal failure are serious complications in coronary artery bypass surgery. Some previous studies indicated minimal renal failure in off-pump surgery when compared

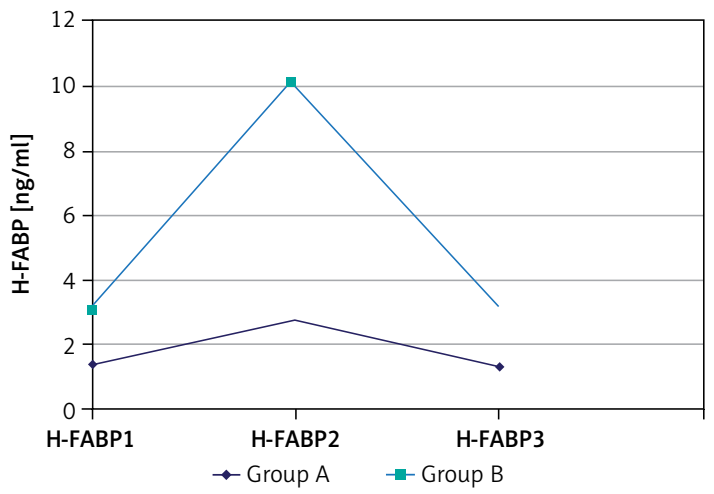

Figure 1. Change of H-FABP levels between assessment points 
with on-pump [14]. In a randomised controlled study on 1580 subjects (1145 off-pump; 435 onpump) Abu-Omar et al. reported better glomerular filtration and renal tubular function in off-pump surgery [15]. On the other hand, Gamoso et al. did not find any significant difference for renal dysfunction between on-pump and off-pump groups [16]. In our study the serum creatinine, BUN, and BUN/creatinine ratio were measured. Our results did not show any significant difference in creatinine and BUN/creatinine ratio in both groups in terms of preoperative and postoperative periods. Only in the on-pump group were BUN levels significantly increased in the postoperative period.

In order to evaluate the myocardial injury in on-pump and off-pump surgery Chowdhury et al. conducted a randomised study on 50 subjects [17]. Cardiac biomarkers including H-FABP, cardiac troponin I, CK-MB, high-sensitivity C-reactive protein, and myoglobin were used. The study results indicated that, among these markers, H-FABP and cardiac troponin I were found to be the most sensitive biomarkers for myocardium injury.

In our study, in order to assess myocardial damage, H-FABP levels were measured. In the healthy population H-FABP levels should be lower than $5 \mu \mathrm{g} / \mathrm{l}$. It can be detected in the serum within $4 \mathrm{~h}$ after myocardial injury. Previous studies reported a close relation between infarct size and amount. In our study, blood samples were obtained immediately after sternotomy (H-FABP 1), after the last distal anastomosis in the off-pump group, after the cross clamp was removed in the on-pump group (H-FABP 2), and at the $24^{\text {th }}$ postoperative hour in both groups (H-FABP 3 ). For first assessment point (after sternotomy) H-FABP median values were measured as $1.40 \mathrm{ng} / \mathrm{ml}$ in group $A$ and $3.10 \mathrm{ng} / \mathrm{ml}$ in group $B$, which was attributed to the increased number of diseased coronary arteries. All of the cases were fully revascularised in the two groups, and the operation technique was also chosen regarding full revascularisation. As a result, the number of affected arteries was accepted as not effecting the ischaemia level of myocardium in the postoperative period. For the second assessment point, in group A, the H-FABP levels increased to $2.75 \mathrm{ng} / \mathrm{ml}$, probably due to the temporary ischaemia during anastomosis. None of the subjects in group A demonstrated a H-FABP value of more than $5 \mathrm{ng} / \mathrm{ml}$. In group $B$ the $\mathrm{H}$-FABP levels increased up to $10 \mathrm{ng} / \mathrm{ml}$, and in two subjects they reached values above $19 \mathrm{ng} / \mathrm{ml}$. In these subjects, it is thought that the existing ischaemia continued in the early period. For the third assessment point, median H-FABP levels decreased to $1.40 \mathrm{ng} / \mathrm{ml}$. One subject in group A demonstrated a high $\mathrm{H}$-FABP level at the $24^{\text {th }}$ postoperative hour $(20 \mathrm{ng} / \mathrm{ml})$. H-FABP levels decreased to $1.40 \mathrm{ng} / \mathrm{ml}$ in follow-up. The increase of $\mathrm{H}$-FABP levels was due to increased drainage and hypotension in this subject. IABP was required in this particular patient due to low blood pressure. In group $\mathrm{B}, \mathrm{H}-\mathrm{FABP}$ levels decreased to $3.20 \mathrm{ng} / \mathrm{ml}$. In both assessment points H-FABP levels were significantly higher in on-pump surgery, indicating increased myocardial injury. This damage was transient, and H-FABP levels returned to preoperative levels $24 \mathrm{~h}$ after surgery.

A major limitation of the study was the small number of the patients in both groups. In group B more saphenous vein grafts were used, which is indicative for more severe coronary artery disease. Disparity of disease severity between groups may be accepted as another major limitation; however, we performed full revascularisation in all of the patients. As another limitation, we should accept the non-randomised nature of the study.

In conclusion, it is well known that off-pump CABG has certain disadvantages, including limited visibility of the coronary arteries and manipulation of the heart; however, several advantages of the technique were outlined in the literature. In our study, we sought to investigate the deleterious effects of $C P B$ on the ischaemic myocardium through H-FABP levels. The H-FABP levels were significantly elevated in patients with coronary artery disease who received on-pump CABG, which indicated myocardial injury.

\section{Conflict of interest}

The authors declare no conflict of interest.

\section{References}

1. Malik V, Kale SC, Chowdhury UK, Ramakrishnan L, Chauhan S, Kiran U. Myocardial injury in coronary artery bypass grafting: on-pump versus off-pump comparison by measuring heart-type fatty-acid-binding protein release. Tex Heart Inst J 2006; 33: 321-7.

2. Khan NE, De Souza A, Mister R, et al. A randomized comparison of off-pump and on-pump multivessel coronary-artery bypass surgery. N Engl J Med 2004; 350: 21-8.

3. Kapoor MC, Ramachandran TR. Inflammatory response to cardiac surgery and strategies to overcome it. Ann Card Anaesth 2004; 7: 113-28.

4. Vedin J, Jensen U, Ericsson A, et al. Cardiovascular function during the first 24 hours after off pump coronary artery bypass grafting: a prospective, randomized study. Interact Cardiovasc Thorac Surg 2003; 2: 489-94.

5. Williams ML, Muhlbaier LH, Schroder JN, et al. Risk-adjusted short- and long-term outcomes for on-pump versus off-pump coronary artery by-pass surgery. Circulation 2005; 112: 1-366-70.

6. Biglioli P, Cannata A, Alamanni F, et al. Biological effects of off-pump vs. on-pump coronary artery surgery: focus on inflammation, hemostasis and oxidative stres. Eur J Cardiothorac Surg 2003; 24: 260-9.

7. Reston JT, Tregear SJ, Turkelson CM. Meta-analysis of short-term and mid-term outcomes following off-pump 
coronary artery bypass grafting. Ann Thorac Surg 2003; 76: 1510-5.

8. Brudney CS, Gosling P, Manji M. Pulmonary and renal function following cardiopulmonary bypass is associated with systemic capillary leak. J Cardiothorac Vasc Anesth 2005; 19: 188-92.

9. Magnusson L, Zemgulis V, Wicky S, Tydén H, Hedenstierna G. Effect of CPAP during cardiopulmonary by-pass on postoperative lung function: an experimental study. Acta Anaesthesiol Scand 1998; 42: 1133-8.

10. Macnaughton PD, Braude S, Hunter DN, Denison DM, Evans TW. Changes in lung function and pulmonary capillary permeability after cardiopulmonary by-pass. Crit Care Med 1992; 20: 1289-94.

11. Houlind K, Kjeldsen BJ, Madsen SN, et al.; DOORS study group. The impact of avoiding cardiopulmonary by-pass during coronary artery bypass surgery in elderly patients: the Danish On-pump Off-pump Randomisation Study (DOORS). Trials 2009; 10: 47.

12. Yamada T, Ochiai R, Takeda J, Kikuchi $H$, Ishibashi $M$, Watanabe K. Off-pump coronary artery bypass attenuates transient hepatocellular damage after myocardial revascularization. J Cardiothorac Vasc Anesth 2005; 19 : 603-7.

13. Möhnle P, Kilger E, Adnan L, Beiras-Fernandez A, Vicol C, Weis $F$. Indocyanine green clearance after cardiac surgery: the impact of cardiopulmonary bypass. Perfusion 2012; 27: 292-9.

14. Ogawa M, Doi K, Yamada Y, et al. Renal outcome in offpump coronary artery bypass grafting: predictors for renal impairment with multivariate analysis. Innovations (Phila) 2007; 2: 192-7.

15. Abu-Omar Y, Taghavi FJ, Navaratnarajah M, et al. The impact of off-pump coronary artery bypass surgery on postoperative renal function. Perfusion 2012; 27: 127-31.

16. Gamoso MG, Phillips-Bute B, Landolfo KP, Newman MF, Stafford-Smith M. Off-pump versus on-pump coronary artery bypass surgery and postoperative renal dysfunction. Anesth Analg 2000; 91: 1080-4.

17. Chowdhury UK, Malik V, Yadav R, et al. Myocardial injury in coronary artery bypass grafting: on-pump versus offpump comparison by measuring high-sensitivity C-reactive protein, cardiac troponin I, heart-type fatty acid-binding protein, creatine kinase- $M B$, and myoglobin release. J Thorac Cardiovasc Surg 2008; 135: 1110-9. 